\title{
GCU
}

Glasgow Caledonian

University

University for the Common Good

\section{The volume and source of cyberabuse influences victim blame and perceptions of attractiveness}

Scott, Graham G.; Wiencierz, Stacey; Hand, Christopher J.

Published in:

Computers in Human Behavior

DOI:

10.1016/j.chb.2018.10.037

Publication date:

2019

Document Version

Author accepted manuscript

Link to publication in ResearchOnline

Citation for published version (Harvard):

Scott, GG, Wiencierz, S \& Hand, CJ 2019, 'The volume and source of cyberabuse influences victim blame and perceptions of attractiveness', Computers in Human Behavior, vol. 92, pp. 119-127.

https://doi.org/10.1016/j.chb.2018.10.037

\section{General rights}

Copyright and moral rights for the publications made accessible in the public portal are retained by the authors and/or other copyright owners and it is a condition of accessing publications that users recognise and abide by the legal requirements associated with these rights.

Take down policy

If you believe that this document breaches copyright please view our takedown policy at https://edshare.gcu.ac.uk/id/eprint/5179 for details

of how to contact us. 
RUNNING HEAD: CYBERABUSE, VICTIM BLAME \& VICTIM ATTRACTIVENESS

\begin{abstract}
Cyberabuse is an escalating problem in society, as opportunities for abuse to occur in online public domains increase. Such acts are often defined by the frequency of abuse, and in many cases multiple individuals play a part in the abuse. Although consequences of such acts are often severe, there is typically little public sympathy/support for victims. To better understand perceptions of victims of abusive online acts, we manipulated the Volume (low, high) and Source (same-source, multi-source) of abusive posts in artificially-manipulated Facebook timelines of four fictitious 'victims'. One hundred and sixty-four participants [United Kingdom-based; aged 18-59] rated 'victims' on measures of direct victim blame (DVB) and perceived social-, physical- and task-attractiveness. Results revealed significant Volume $\times$ Source interactions on DVB and social-attractiveness ratings. Few abusive posts authored by a single source yielded higher DVB and lower social-attractiveness ratings. Strong correlations between attractiveness and DVB were observed. We propose that our results could be due to an observer desensitization effect, or that participants interpreted the posts as indicative of friendly 'teasing' or 'banter' within an established social relationship, helping to explain why victims of online abuse often receive little sympathy or support.
\end{abstract}

Keywords: $\quad$ cyberabuse; cyberbullying; social networking; victim blame; attractiveness; Facebook 


\section{Introduction}

Abusive online behavior is a growing problem in society (Dooley, Pyzalski, \& Cross, 2009; Selwyn, 2008). One common example of this is the sending of direct abusive messages via public online forums, such as social media. Despite the harmful effects of this kind of cyberabuse (including cyberbullying and cyberstalking; Hinduja \& Patchin, 2010), public support and sympathy for victims is low (Maple, Short, Brown, Bryden, \& Salter, 2012). To better understand how acts of online abuse are viewed and interpreted, we manipulated the Volume and Source of online abuse within artificially-constructed Facebook timelines of four 'victims', and measured participants' victim-blame attribution and perceptions of victim attractiveness.

\subsection{Social media and cyberabuse}

Rapid evolution of mobile technologies and online social media has contributed to an increase in cyberabuse. Increased availability of mobile devices means that individuals are constantly connected to the internet and social media regardless of location (Freis \& Gurung, 2013; Smith, 2012). The integration of digital media such as social networking sites (SNSs) into everyday life has meant new, more public forums in which acts of abuse can occur (Smith, 2012). Abusive messages posted on such forums represent a damaging and highly visible form of online aggression that can contribute to a number of categories of online abuse, such as cyberbullying and cyberstalking (Maple et al., 2012; Menesini \& Nocentini, 2009). Prevalence of cyberabuse has been reportedly as high as $40 \%$ (Perren, Dooley, Shaw, $\&$ Cross, 2010), though a meta-analysis estimates the average to be $\sim 15 \%$ (Modecki, Minchin, Harbaugh, Guerra, \& Runions, 2014). Cyberabuse among adults is thought to be just as prevalent as amongst children (Einarsen \& Skogstad, 2008; Spence Laschinger \& Nosko, 2013), with college/university students particularly at risk because of their high level 
of social media and communication technology use and reduced parental supervision (Kota, Schoohs, Benson, \& Moreno, 2014). There is no clear divide between on- and off-line abuse: $85 \%$ of traditional bullying in schools occurs simultaneously online (Juvonen \& Gross, 2008), while $39 \%$ of adult stalking victims report both off- and on-line contact (Sheridan \& Grant, 2008).

Due to the diverse and evolving nature of cyberabuse, definitions of specific categories of abuse are not always consistent across studies (Menesini et al., 2012; Selwyn, 2008) and specific online acts may contribute towards the criteria for more than one distinct category of online abuse (e.g., cyberbullying and cyberstalking). Cyberbullying, for example, has been defined as an aggressive act perpetrated via electronic contact (Menesini \& Nocentini, 2009), focusing on intent to harm and the persistence and repetition of abusive acts (Bocij, 2004; Mullen, Pathé, \& Purcell, 2004; Novo, Pereira, \& Matos, 2014; Olweus, 2012; Reyns, 2010). Cyberstalking involves similar behaviors but is typically perpetrated by a solitary individual with a preoccupation towards the pursued individual with a focus on gaining attention (Sheridan \& Grant, 2008). Early research into cyberabuse commonly confused these labels, with cyberstalking sometimes employed as a label of cyberbullying between adults (rather than children or adolescents; Fegenbush \& Oliver, 2009).

A behavior common to many types of online abuse, including cyberbullying and cyberstalking, is the sending of abusive messages online, including on public forums like SNSs (e.g., Facebook). Two factors common in definitions of both cyberbullying and cyberstalking are frequency, or volume, of abuse and the number of perpetrators involved. Specific details often diverge in different cases of cyberabuse. While commonly measured in isolation, the combined effects of a varying volume of abuse from a varying number of perpetrators on impressions formed of the victim by bystanders, is somewhat under investigated. 


\subsection{Volume and Source effects in cyberabuse}

Frequency of abuse (rather than an isolated incident) manifests on the online record (e.g., on social media) as a volume of abuse accumulated over time. Many definitions of cyberbullying necessitate that the abuse must be a repetitive action (e.g., Kowalski, Limber, \& Agatston, 2009; Langos, 2012; Menesini \& Nocentini, 2009; Vandebosch \& Van Cleemput, 2008). A recent systematic review of cyberbullying literature reported that most studies conducted between 2013 and 2015 used frequency as a descriptive measure (Garett, Lord, \& Young, 2016). Incidences of cyberstalking are also characterised by multiple incidences of contact or abuse (e.g., Citron, 2009; Sheridan \& Grant, 2008). Although common in definitions, the impact of different frequencies of repetition, or volume of abuse posted online, has not been investigated in relation to the perceived severity of online abuse.

Often multiple perpetrators contribute to online abuse. Cyberbullies commonly have assistants and/or defenders (e.g., Smith et al., 2008) and trick other users into abusing victims (Finn, 2004; McGrath \& Casey, 2002; Spitzberg \& Hoobler, 2002). As such, potential multiple perpetrators are included in many definitions of cyberbullying (Menesini \& Nocentini, 2009; Smith et al., 2008; Tokunaga, 2010). Cyberbullying in Germany is often called 'cybermobbing' as it is common for multiple individuals to bully one victim (Nocentini et al., 2010). Additionally, even though only one perpetrator may be involved, that individual may use multiple online identities when contacting a victim (Kowalski et al., 2009). Although the effect of the group has been shown to have distressing impact in traditional offline bullying (e.g., Crick, Grotpeter, \& Bigbee, 2002; Salmivalli, 2010) this aspect of cyberbullying has not been explored. Although less common, stalking by groups of individuals, or 'mobs', has also been reported (Citron, 2009) and, as in cyberbullying, 
cyberstalkers are also known to use multiple online identities (Alexy, Burgess, Baker, \& Smoyak, 2005).

As with volume, although often included in definitions or reported in case studies, whether being the victim of single or multiple perpetrators effects the severity of abuse experienced by cyberbullying victims or the perceptions formed by online observers, has not been investigated. Similarly, although cyberstalkers are known to commonly utilize numerous online identities, the impact of them doing so, on both the victim and on observers (who would view such acts as abuse by multiple individuals), remains under-investigated. By experimentally manipulating both the Source of online abuse (single vs. multiple perpetrator) and its frequency (Volume), we will investigate for the first time the role played by these two factors on impressions of online abuse, providing insight into perceptions formed of cyberabuse victims.

Direct messages on SNSs from the perpetrator to the victim are digital records of cyberabuse, common in, but not limited to, cyberbullying and cyberstalking. These not only impact the victim but form a potentially public record of the abuse. Such deviant acts can produce profound negative psychological effects: depression, anxiety, lowered self-esteem (Mechanic, Uhlmansiek, Weaver, \& Resick, 2000; Short \& McMurray, 2009). The resultant distress can impact academic performance (Copeland et al., 2014), force behavioral and lifestyle changes (van Geel, Vedder, \& Tanilon, 2014) and even result in suicide (Hinduja \& Patchin, 2010; McQuade, 2012). Around one-third of cyberstalking victims scored highly for symptoms of PTSD, equivalent to victims of sexual assault and survivors of combat and bombings (Maple et al., 2012). Aggressive online acts may be so profound because of the importance of the internet in victims' lives, and lack of perceived escape routes (Juvonen \& Gross, 2008). 


\subsection{Bystander perceptions and behaviors}

Despite these consequences there is a perceived lack of support for victims of cyberabuse. Many students believe that their institution is not sensitive to issues of cyberbullying, and that their professors are not knowledgeable about the phenomenon (Molluzzo \& Lawler, 2012). Students are typically also unaware of institutional policies or intervention strategies concerning online abuse (Baldasare, Bauman, Goldman, \& Robie, 2012; Molluzzo \& Lawler, 2012). College students will normally make no attempt to report an incident of online abuse if they observe it (Crosslin \& Golman, 2014; Gahagan, Vaterlaus, \& Frost, 2016) and social support is negatively related to depression in adult cyberbullying victims (Tennant, Demaray, Coyle, \& Malecki, 2015). Cyberstalking victims typically receive little support from peers or authorities (Maple et al., 2012) and the same actions are judged as 'stalking' offline but 'romantic' online (Lee, 1998).

Thornberg et al. (2012) emphasise that bystander perception of bullying behavior can be shaped by numerous factors, including the context of the interaction and the social relationship(s) between the individuals concerned. It has been argued that victims of cyberabuse may be at-risk of experiencing greater harm than victims of traditional face-toface bullying, as the nature of the online environment potentially facilitates negative (cyber)bystander behavior (Barlinska, Szuster, \& Winiewski, 2013). Barlinska et al. identified the existence of opportunities for bystanders to disseminate abusive content via features of the online platform, or by reposting the material to an alternative social media environment.

It is hugely important to understand bystander responses when exposed to acts of cyberabuse, given its emergence as an increasingly widespread source of harm to victims. Online abuse, particularly potentially permanent abusive messages written on public forums such as SNSs, will inevitably be viewed by more witnesses than traditional offline acts of 
aggression. Understanding how such acts are viewed by observers could provide insight into their likelihood to intervene, either providing support to the victim or joining in with the perpetrators(s) of abuse and exacerbating the situation. Multiple studies have considered bystander behavior when cyberbullying has been encountered. For example, the behavior of female college students (cyber)bystanders was investigated by Freis \& Gurung (2013). The authors developed a paradigm which involved an online live chat between each participant, a confederate playing the role of 'bully' and another confederate playing the role of 'victim'. Participant bystanders could generate a number of responses during the interaction, which were categorised as: "stop/bully;" facilitate discussion; (attempt to) change the topic of the chat; console the 'victim'; aggress towards the 'bully'; pass; or 'other'. Over $90 \%$ of participants exhibited at least one intervention behavior and almost half were prepared to "pass" (i.e., not intervene) at least once during the abusive interaction. The most likely forms of intervention were indirect rather than direct (e.g., changing the topic, avoiding the topic vs. making a "stop" response, "bully" response or supporting the 'victim'; Freis \& Gurung, 2013).

Shultz, Heilman \& Hart (2014) conducted a study in which participants were presented with a 'conversation' from Facebook wherein two individuals abused a third individual based on their behavior at a recent party. Participants were instructed to imagine that those involved were close high school friends. After reading the first part of the conversation, participants were asked which agent they most identified with (i.e., 'victim' or one of the 'bullies'). This was followed by an open-response question which asked the participants at which point the would join the interaction and what would their comment be (if any), before a final question as to the motivations of the (cyber)bystanders (why they would or would not comment on the conversation). Following these responses, participants were presented with a continuation of the conversation - wherein progressive comments 
increased in vitriol - before answering the same series of questions again. Finally, participants were asked to identify at which point in the conversation that they considered bullying to have occurred (or respond that they thought no bullying had occurred), and to expand and explain their choice of response.

Analyses of participant responses demonstrated that approximately $91 \%$ of participants identified that cyberbullying had occurred; however, fewer than half indicated that they would exhibit a victim-supportive intervention strategy - demonstrating negative bystander behavior. A small sub-group of participants responded that they would post comments which aligned (or joined in) with the 'bullies', indicating they drew enjoyment from participating in negative interactions (Shultz et al., 2014). Among the themes which emerged from participant responses were related to whether Facebook was an appropriate platform for the initial post by the 'victim' and that the 'victim' should be active in deleting the initial status. Furthermore, certain participants responded that they found the initial post and subsequent conversation to be immature and / or that the participant had negative views as to the topic of conversation (i.e., overconsumption of alcohol). Taken together, these findings indicate that (cyber)bystanders believe the 'victim' to have a level of control over the situation and should potentially assume responsibility for the content of the conversation which follows the initial 'victim' post (Shultz et al., 2014).

\subsection{Blaming the victim}

Lack of support and negative bystander behavior could be caused in part by victim blame (VB) - wherein the victims of crimes are attributed blame for the acts perpetrated against them (e.g., Russell \& Hand, 2017). Explanations for such attributions include Just World Theory: a belief that the world is a just place and people 'get what they deserve' (Lerner \& Simmons, 1966), and the Defensive Attribution Hypothesis: a desire to attribute 
the attack to a victim's disposition, increasing one's own sense of control (Shaver, 1970). Indeed, DeSmet et al. (2012) reported that participants perceived that acts of cyberbullying were fair if it were possible to blame the victim for their own initial behavior. Weber, Ziegele \& Schnauber. (2013) examined the circumstances in which peers / bystanders / observers are likely to support a victim of cyberbullying, within a framework of psychological victim blaming. The authors hypothesised that the more personal information that the victim disclosed (to strangers), the more likely that bystanders would engage in victim blaming. Weber et al. also hypothesised a mediating influence of victim attractiveness - such that higher victim attractiveness would be associated with lower VB.

In an online experiment, profile owner - 'victim' - Extraversion (high vs. low) and Volume of information disclosed (high vs. low) were manipulated. Participants $(N=586$, ages 16-22 years) were provided with a short scenario that described a young female - Sophia - being subjected to cyberbullying after an ambiguous confrontational event. Participants were then presented with one of four versions of the fictional student's Facebook profile, which presented the student as extraverted or introverted (as determined by the content of the student's profile picture) and presented either a high or low volume of disclosed information. Finally, participants were asked outright who was to blame for the incident on a five-point Likert-type scale. Responses to the outright blame measure were statistically well-explained by the measures of DVB and IVB. Participants were also asked to rate the victim's perceived attractiveness on a five-point Likert-type scale $(1=$ "Sophia is attractive" to $5=$ "Sophia is unattractive").

Structural equation modelling was used to examine the relationships between variables. Participants who saw that Sophia had disclosed a high volume of information publicly were more likely to find her responsible for her own victimization. Higher perceived attractiveness reduced the likelihood that participants would attribute blame to the victim. A 
large volume of publicly disclosed information led to greater victim blaming; however, victim attractiveness partially supressed these effects - bystanders gave more social support to a victim perceived as attractive. Information disclosure is argued to rationalize the victim blaming, inferring provocative behavior.

Such effects might be facilitated by a reverse halo effect: just as impressions formed of physically attractive individuals assume they possess other positive traits ("what is beautiful is good": Dion, Berscheid, \& Walster, 1972), physically unattractive individuals are assumed to possess negative traits ("ugly-is-bad"; McKelvie \& Coley, 1993). In online environments, which are impoverished vs. cue-rich real-world contexts, impressions of individuals are often formed quickly based on a few salient cues, such as attractiveness (Hancock \& Dunham, 2001; Walther, 1996; 1997). In the context of VB, this could potentially result in more negative impressions being formed of less physically attractive individuals, and thus increased culpability and blame for any assault perpetrated against them (Weber et al., 2013).

Weber et al. (2013) focussed their research on the quality and quantity of information disclosed by the victim about themselves, whereas the current study examines the quality, quantity and source nature of information directed towards the victim. They examined the relationship between victim presentation and likelihood of blame attribution, whereas the current research examines how negative information targeted at a victim influences bystander perception of that victim. It is also possible that the narrow age range of Weber et al.'s participants - adolescent and young adult participants - limits the generalizability of the results from their research; furthermore, the use of only one 'victim' - a young female - may limit the generalizability of the results, and that the vignette employed may have resulted in short-term priming effects. Therefore, the current research examined a broader range of 
participant ages, carefully controlled and counterbalanced the gender of the victim, and avoided any disclosing any information about the victim's prior history.

In the online impression formation literature, attractiveness is typically measured as comprising three distinct components: social-, physical-, task- (McCroskey \& McCain, 1974). Social attractiveness refers to the individual's social allure, physical attractiveness to their beauty, and task attractiveness to their appeal as a work colleague. Perceptions of these distinct dimensions have been shown experimentally to be differentially influenced by distinct SNS components such as online friends and profile/timeline content posted by others (e.g., Rosenthal-Stott, Dicks \& Fielding, 2015; Scott, 2014; Scott \& Ravenscroft, 2017; Scott, Sinclair, Short, \& Bruce, 2014; Tong, Van Der Heide, Langwell, \& Walther, 2008; Walther, Van Der Heide, Hamel \& Shulman, 2009; Walther, Van Der Heide, Kim, Westerman \& Tong, 2008). Although Weber et al. found their effect of VB partially mediated by the perceived attractiveness of the victim, they measured 'attractiveness' on a single, somewhat ambiguous item. This may have been interpreted by respondents as referring to one or more of these facets. We measured each attractiveness dimension separately, and by doing so aim to provide insight into the relationship between these specific aspects of attractiveness and perceived VB. By doing this we aim to identify the aspect of attractiveness most connected to online VB.

\subsection{The current study}

The current study explored adults' perceptions of cyberabuse victims. We manipulated two established dimensions of both cyberbullying and cyberstalking: Volume of abuse (Mullen et al., 2004) and its Source (Finn, 2004; Salmivalli et al., 1996). A 2 (Volume: low, high $) \times 2$ (Source: same-source, multi-source) repeated measures experimental design was employed. As we manipulated the quantity and source nature of information directed 
towards the victim, we concentrated on the measure of DVB as opposed to the measures of IVB or the single-item measure used by Weber et al. (2013). We predicted an interactive effect of Volume and Source of abuse on both DVB and perceived victim attractiveness. It may be that a high volume of abusive content generated by multiple 'friends' facilitates a just-world perception and that the profile owner must somehow be responsible for inciting the cyberabusive behavior (Lerner \& Simmons, 1966). High-volume multi-source abuse may also / alternatively drive defensive attribution to protect the bystander's own self-concept (Shaver, 1970), therefore resulting in greater DVB. On the other hand, based on the findings of Shultz et al. (2014), if bystanders perceive the high-volume interactions between multiple users as teasing or banter among close friends, it is possible that the 'victim' might appear popular (socially-attractive), and thus be attributed towards positively (e.g., Dion et al., 1972) and therefore be less likely to be blamed. We predicted that DVB would negatively correlate with perceived social-, physical- and task-attractiveness (e.g., Dion et al., 1972; McKelvie \& Coley, 1993).

\section{Method}

\subsection{Participants}

A total of 164 volunteers (59 males; $M_{\text {age }}=23.54$ years, $S D_{\text {age }}=7.12 ;$ range: $\left.18-59\right)$ participated for either $£ 5$ or course credit. All participants were undergraduates at a British university and identified as: 98 British, 54 European, eight Asian, three American, and one Chilean. Participants were active Facebook users.

\subsection{Design}

A 2 (Volume: low, high) x 2 (Source: Same-source, multi-source) repeated-measures design was employed. Dependent variables were DVB (Weber et al., 2013) and social-, 
physical-, and task-attractiveness (McCroskey \& McCain, 1974). A four-item, five-point Likert-type scale was used to measure DVB. Participants disclosed their agreement with statements such as "The profile owner provoked any negative tweets sent to them" on a scale from Strongly Disagree (1) to Strongly Agree (5); analysis revealed that participant responses to this scale were reliable (Cronbach's $\alpha=0.820$ ). Each sub-type of attractiveness was measured on five-item, seven-point Likert-type scales. Participants disclosed their agreement with statements such as "I think he (she) could be a friend of mine." [social attractiveness], "I find him (her) very attractive physically" [physical attractiveness] or "I couldn't get anything accomplished with him (her)." [task attractiveness] from Strongly Disagree (1) to Strongly Agree (7). Reverse coding was employed where appropriate, and analyses revealed that participant responses to these sub-scales were reliable (Cronbach's $\alpha=0.844,0.815$ and 0.842 respectively).

\subsection{Materials and procedure}

Participants saw screenshots of eight Facebook timelines, each differing in the Volume, Source(s), and valence of posts they contained. Volume was defined by the number of 'friend'-authored posts a timeline contained: those containing a 'low' volume of abuse consisted of two 'friend'-authored posts and six pieces of non-personalised content shared by the timeline owner; those containing a 'high' volume of abuse consisted of six 'friend'authored posts and two pieces of non-personalised shared content. Each timeline was equal in physical length. The 'low' volume number was set at two posts because that was the smallest number within which Source could be still be manipulated, and six posts chosen as the high because that was the maximum number which could fit onto a timeline image covering two 'pages' of a lab computer screen. Source was defined by the 'friends' who authored the posts: on 'same-source' timelines all 'friend'-authored posts were posted by a single 'friend', on 
'multi-source' timelines each post was authored by a different 'friend'. Valence was defined by the nature of 'friend'-authored posts: four timelines contained exclusively positive posts, four contained exclusively negative posts (e.g., "I hate you so much"; "DIE"). As perceptions relating to online abuse was our focus, only data relating to the negative timelines was examined; however, it was important that participants viewed all eight timelines so that they were exposed to a balanced set of stimuli, minimizing possible desensitization.

On all timelines, the top (most recent) content was a 'friend'-authored comment. All other salient profile details (e.g., profile picture attractiveness, number of friends/photos) were carefully controlled and counterbalanced (Scott \& Hand, 2016). Profile pictures were taken from a set originally published by Welling et al. (2007). Models were undergraduate students, although their ages were not specified on timelines. Half of the timeline owners were male and half were female; all were Caucasian. An example stimulus is included in Appendix I.

Twenty independent participants [all undergraduate students: 10 males; $M_{\text {age }}=20.90$ years, $S D_{\text {age }}=3.29$; range: $\left.18-32\right]$ normed the content of timeline posts. Positive, negative and filler posts were pseudo-randomised and presented to raters via Qualtrics web-based surveys. Evaluators were asked to rate each on a response scale of -3 (highly negative) to +3 (highly positive; 0 being 'neutral'). Means were: $M_{\text {neg }}=-2.49\left(S D_{\text {neg }}=1.12 ; 95 \%\right.$ CI: -2.63 to $-2.35) ; M_{\text {pos }}=2.57\left(S D_{\text {pos }}=1.10 ; 95 \%\right.$ CI: 2.43 to 2.71$)$. Therefore, we were confident that our experimental posts were sufficiently negative/positive.

Participants were recruited via adverts around campus and electronically via the student participant pool and viewed the timelines in experimental booths on campus. They were instructed to view the timelines as they would those of a friend for as long as they wanted to form an impression, before completing the questionnaires. Profiles were presented to participants in one of eight counterbalanced orders. Upon completion, participants were 
debriefed as to the purpose of the experiment. The experiment was approved by the School's ethics committee.

\section{Results}

We conducted a total of four 2 (Volume: low, high) $\times 2$ (Source: single-source, multisource) repeated-measures analyses of variance (ANOVAs) on measures of DVB and social-, physical-, and task-attractiveness. Means and SDs are presented in Table 1, and ANOVA results are summarised in Table 2. 
Table 1

Means (Standard Deviations) of Direct Victim Blame and perceived social-, physicaland task-attractiveness.

\begin{tabular}{lcccc}
\hline Volume & \multicolumn{2}{c}{ Low } & \multicolumn{2}{c}{ High } \\
Source & Single & Multi & Single & Multi \\
\hline DVB & $9.68(3.90)$ & $9.37(4.05)$ & $8.99(3.73)$ & $9.37(4.26)$ \\
SocAtt & $20.19(6.17)$ & $21.21(5.84)$ & $21.98(6.45)$ & $20.95(6.33)$ \\
PhyAtt & $18.37(5.48)$ & $19.22(5.86)$ & $18.96(6.23)$ & $19.82(6.10)$ \\
TaskAtt & $19.72(2.67)$ & $19.57(2.74)$ & $19.41(2.38)$ & $19.68(2.69)$ \\
\hline
\end{tabular}

Note. $\quad$ DVB $=$ Direct Victim Blame; SocAtt/PhyAtt $/$ TaskAtt $=$ Social-/Physical-/Taskattractiveness.

Table 2

ANOVA results

\begin{tabular}{lccccccccc}
\hline & \multicolumn{3}{c}{ Volume } & \multicolumn{3}{c}{ Source } & \multicolumn{3}{c}{ Volume $\times$ Source } \\
Measure & $F$ & $p$ & $\eta_{p}^{2}$ & $F$ & $p$ & $\eta_{p}^{2}$ & $F$ & $p$ & $\eta_{p}^{2}$ \\
\hline DVB & 2.44 & .120 & 0.015 & $<1$ & & & 4.95 & .027 & 0.029 \\
SocAtt & 3.32 & .070 & 0.020 & $<1$ & & & 7.95 & .005 & 0.047 \\
PhyAtt & 1.95 & .165 & 0.012 & 3.72 & .055 & 0.022 & $<1$ & & \\
TaskAtt & $<1$ & & & $<1$ & & & 1.26 & .263 & 0.008 \\
\hline
\end{tabular}

Note. Degrees of Freedom $(1,163) . \mathrm{DVB}=$ Direct Victim Blame; SocAtt $/$ PhyAtt $/$ TaskAtt $=$ Social-/Physical-/Task-attractiveness. $\eta_{p}^{2}=$ partial eta squared.

\subsection{Victim Blame}

There was a significant Volume $\times$ Source interaction for DVB (see Table 2 and Figure 1). Within single-source abuse, the simple main effect of Volume was significant: those receiving few posts were attributed more blame (9.683) than those receiving many 
posts $(8.994 ; p=.007)$; all other contrasts were non-significant. No other main effects or interactions were significant.

Figure 1

Volume $\times$ Source interactions with Social Attractiveness and Direct Victim Blame
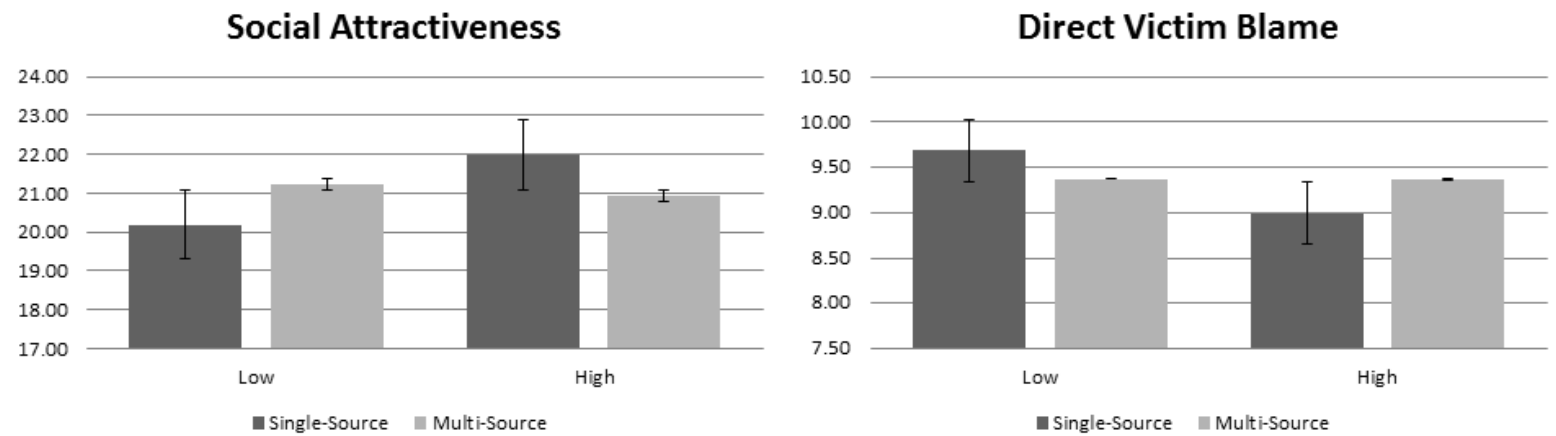

Note. $\quad 2$ (Volume: low, high) $\times 2$ (Source: single-source, multi-source) repeated-measures ANOVA interaction means (standard errors).

\subsection{Attractiveness}

There was a marginal main effect of Volume on social-attractiveness (see Table 2) with 'victims' rated as more attractive when their timeline contained many vs. few posts (21.463 vs. 20.701). The main effect of Source was non-significant, but there was a significant Volume $\times$ Source interaction (see Table 2 and Figure 1). When abuse was lowvolume, victims were seen as more socially-attractive if the abuse came from multiple sources $(21.213)$ than from a single source $(20.189 ; p=.050)$. When abuse was high-volume, participants were perceived as more socially-attractive when the abuse came from the same source (21.982) than from different sources $(20.945 ; p=.045)$. When abusive content was generated by a single 'friend', victim social-attractiveness was significantly higher if the single source posted many comments (21.982) than if they posted few $(20.189 ; p=.003)$; 
there was no significant difference in perceptions of victim social-attractiveness in multisource abuse dependent on volume.

There was a marginal effect of Source on physical-attractiveness (see Table 2), with those whose timeline contained multi-source posts (19.39) rated more physically-attractive than those whose timeline contained posts from a single source (18.67). There were no other main effects or interactions for physical- or task-attractiveness.

\subsection{Correlations of Perceptions}

A series of one-tailed Pearson's correlations were performed to investigate relationships between perceptions of attractiveness and DVB. It was anticipated that there would be moderate-to-strong negative correlations between DVB and perceived attractiveness. All assumptions for the analyses were met, and results are summarised in Table 3 .

Table 3

\begin{tabular}{lccccc}
\hline Measure & & DVB & SocAtt & PhyAtt & TaskAtt \\
\hline DVB & $r_{s}$ & - & -.270 & -.242 & -.290 \\
& $p$ & - & $* * *$ & $* *$ & $* * *$ \\
SocAtt & $r_{s}$ & & - & .605 & .270 \\
& $p$ & & - & $-* *$ & $* * *$ \\
PhyAtt & $r_{s}$ & & & - & .223 \\
& $p$ & & & & $* *$ \\
TaskAtt & $r_{s}$ & & & - \\
& $p$ & & & & -
\end{tabular}

Note. $\quad N=164 . \mathrm{DVB}=$ Direct Victim Blame. SocAtt $/$ PhyAtt $/$ TaskAtt $=$ Social-/Physical/Task-attractiveness; $* *=p<.01, * * *=p<.001$ 
As can been seen in Table 3, all correlations were highly significant; therefore, our hypotheses as to the inverse relationship between DVB and perceived attractiveness can be upheld.

\section{Discussion}

The current study examined perceptions of cyberabuse victims in order to investigate the effects of Volume and Source of abusive posts on perceptions of 'victims'. We orthogonally manipulated the Volume and Source of abuse posted on artificial Facebook timelines and measured the attributed DVB and perceived social-, physical-, and taskattractiveness of 'victims'. Significant interactions between Volume and Source were observed on perceptions of DVB and social-attractiveness. When examining the DVB data, one striking result was the simple main effect of Volume within single-source abuse: a low volume of single-source abusive posts on a timeline resulted in greater DVB than a high volume from a single source.

There are a number of explanations for this pattern of data. Abuse on individuals' timelines may have more impact when occurring in isolation (especially if in a position of high perceptual salience, near to the top of the timeline, as in the current study; see Scott \& Hand, 2016); many negative posts could result in viewer desensitization, leading to lower perceived severity. Exposure to violent stimuli reduces sensitivity to such content (e.g., Bartholow, Bushman, \& Sestir, 2006); thus, it is reasonable to extrapolate between the desensitizing effects of violent media and the high-volume abusive content in the present study. The abusive posts were generated by a Facebook 'friend' of the 'victim' - in the situation where many multiple negative posts were made by a single source, it is possible that these interactions were perceived as playful or "fun" between friends, similar to the data obtained by Shultz et al. (2014). 
A significant - but mirrored - Volume $\times$ Source interaction was observed in participants' perceptions of social-attractiveness. 'Victims' were rated as least sociallyattractive when the same source wrote only a few negative posts on their wall, compared to many abusive posts by same or different individuals; phrased alternatively, a few abusive posts - but generated by multiple 'friends' and many abusive posts generated by a single 'friend' resulted in higher perceived social attractiveness. As with the DVB results above and the work of Shultz et al. (2014), it may be the case that when observers view multiple interactions between online associates (either few posts by many individuals, or multiple posts by a single individual) in a closed environment (i.e., Facebook friends), that the communication is perceived as teasing, banter or a dark friendship - and the 'victim' is therefore perceived as more 'socially-attractive' (i.e., they must be somewhat likeable to 'receive the attention').. The mirrored patterns of DVB and social-attractiveness attributions suggest an important relationship between these variables. It appears that the least sociallyattractive 'victims' are also the 'victims' who are held most culpable for their abuse. Examination of correlational data indicated a robust negative correlation between attributed VB and perceived social-attractiveness - with more blame attributed to less attractive victims and vice versa (see Table 3 ).

\subsection{Perceived Social Attractiveness as a Driver of Victim Blame}

We propose that our findings are driven by perceived social attractiveness. Many studies have investigated impression formation in zero-acquaintance relationships via SNSs (i.e., when participants are unfamiliar with the targets about which they are required to form impressions; Scott et al., 2014; Walther et al., 2008). Under such conditions, number of online friends is a reliable indicator of online popularity, influencing perceptions of attractiveness (Scott, 2014; Tong et al., 2008; Utz, 2010). In the current study number of 
'friends' was controlled. However, high-volume abuse timelines necessarily contained more third-party content, i.e., content posted to the timeline by friends rather than by the timeline owner themselves. The number and diversity of online friends posting content on targets' timelines could be used more as indicators of attractiveness than total number of friends, or the negative content of the posts, leading to increased perceptions of social-attractiveness. If effects were driven by perceptions of social-attractiveness, DVB would be affected as it is directly related to judgments about victims' disposition (Lerner \& Simmons, 1966; Weber et al., 2013); our results support such a contention.

Friends' content on private social networks may not be viewed in the same way as third-party content in a more open domain, such as an online forum. On Facebook, for example, friends are always approved by users and are almost exclusively from established offline relationships (Ellison, Steinfeld, \& Lampe, 2007; Skowronski \& Ambady, 2008; Stefanone, Lackaff, \& Rosen, 2011). Therefore, the perceptions of our observers - who had no knowledge of profile owners - nor their relationships with the authors of the Facebook timeline posts - may have failed to encompass the true relationships and nature of the comments passed between timeline owner and 'friend'. In terms of explaining the different effects of Volume, it may have been the case that a high volume of negative posts from a single-source were in fact indicative of a more good-natured, albeit dark, relationship between the profile owner and their 'friend' (e.g., Shultz et al., 2014). Friendly teasing is a normal part of human interaction which can strengthen bonds between individuals and facilitate the development of friendship and solidarity (Tragesser \& Lippman, 2010). When unwanted, however, it can be hurtful and a source of major stress for the receiver (e.g., Hoover \& Olson, 2000). Particularly in online contexts, where fewer contextual cues are available than offline environments, the difference may be harder to identify, particularly for zero-acquaintance observers (Parks \& Floyd, 1996). 


\subsection{Dimensions of Attractiveness}

All of our correlations were in the predicted direction based on Weber's et al.'s (2013) results: more DVB was associated with less-attractive 'victims'. Weber et al. measured 'attractiveness' on a single, somewhat ambiguous, five-point Likert-type scale; we measured 'attractiveness' across three dimensions (social-, physical-, task-; McCroskey \& McCain, 1974). As described above, social-attractiveness is more sensitive to indicators of online popularity than physical- or task-attractiveness (Scott, 2014; Tong et al., 2008). Global correlational analyses revealed that social-attractiveness varied with DVB (collapsing across Volume and Source(s)).

By explicitly measuring three distinct dimensions of attractiveness (social, physical, and task) we have identified social-attractiveness as being the key dimension related to VB. All three attractiveness dimensions were negatively correlated with attributed DVB, but only social (significantly) and physical (marginally) were affected by manipulations of Volume and Source. Posts - even abusive posts - from multiple sources impacted on these dimensions. Both dimensions have been shown to be differentially impacted by cues relating to popularity, suggesting that how popular a timeline owner is perceived to be may contribute to attribution of blame (Scott, 2014; Tong et al., 2008). These findings suggest not only that social-attractiveness is the dimension most closely associated with DVB, but that taskattractiveness is least related to DVB. While task-attractiveness has been shown to be relevant in other facets of online impression formation (e.g., perceived employability: Scott et al., 2014), it is unrelated to perceived VB in the current study, although it would be interesting to see if it is related to DVB in specific cases of online workplace bullying.

\subsection{Theoretical Explanations}


Weber et al. (2013) focussed their research on the information disclosed by the victim, whereas the current study examined the effects of information directed towards the victim. The current study found an opposite effect of volume of information - timelines in our study with fewer negative posts directed at the timeline owner resulted in more DVB; Weber et al. found that the more information posted by the profile owner effected more DVB. Our stimuli containing 'few' abusive posts necessarily contained more shared content by timeline owners - though non-personalised - this could have contributed to higher VB in these conditions, but cannot explain the interaction with Source.

Weber et al. (2013) tested 16-22 year olds; we found similar effects in an exclusively adult population. This demonstrates that interpretation of cyberabusive acts and their impact on perceptions of victims are similar across ages, and contributes to explanations of the limited sympathy and support offered to cyberabuse victims (Hinduja \& Patchin, 2010). This relates to existing theories such as Belief in a Just World (Lerner \& Simmons, 1966): individuals believe that the world they live in is fair; the Defensive Attribution Hypothesis (Shaver, 1970): individuals believe that negative outcomes are less likely to impact those they view as like themselves; and the Halo effect (Thorndike, 1920): those considered attractive will be assumed to possess several other positive traits. As typical healthy individuals think of themselves as being above average, if they form an impression of a third party who is attractive, and therefore possessing many other positive characteristics, it is likely they will consider this third party to be a good person, like themselves. Implicit beliefs that bad things are more likely to happen to bad people, and to people dissimilar to oneself, that third party would thus be attributed less blame for any negative act perpetrated against them, such as cyberabuse.

The 'victims' in the current study were rated as more socially-attractive if they received a high volume of (negative) communications, particularly when abusive content was 
generated by a single 'friend'. Although at first somewhat unexpected, this finding is plausibly explained by both theory and previous research. If the interaction is perceived as 'teasing' between close friends (e.g., Shultz et al., 2014) - an intimate social interaction, perceptions of social-attractiveness could increase and the more visible this interaction (i.e., the higher volume of posts), the larger this effect would be. Conversely, fewer 'friend' generated posts would make the 'victim' appear less socially-attractive.

Perceptions of attractiveness are known to drive perceptions of other characteristics, with more attractive individuals rated more positively than those perceived to be less attractive (e.g., Dion et al., 1972; McKelvie \& Coley, 1993; Thorndike, 1920). It is also wellestablished that observers associate bad things as happening to bad people - either because of a belief in a just world (e.g., Lerner \& Simmons, 1966) or as a mechanism of psychological self-defence (e.g., Shaver, 1970). We observed that all our measures of attractiveness (social-, physical- and task-) all correlated negatively with DVB. Furthermore, we observed that the highest ratings of social-attractiveness were associated with single-source high-volume abuse - suggesting that these socially-attractive profile owners were either not perceived as 'victims' (i.e., being teased) or that their attractiveness led to observers to perceive the 'victims' more positively and therefore apportion blame for the negative content to the abuser rather than the profile owner. In contrast, the highest levels of DVB were associated with the lowest ratings of social-attractiveness, suggesting that this abuse was either seen as targeted and vindictive rather than 'banterous', or that these unattractive individuals were perceived negatively in general and were therefore seen as culpable for their own abuse.

\subsection{Limitations and Future Directions}

It should be acknowledged that this study focused solely on abuse in a public forum, whereas much cyberabuse occurs via covert and private communications (Copeland et al., 
2014). Although our results are valid in the context of impression formation, as observers would likely not be privy to private messages, no conclusions should necessarily be drawn from these results on the impact of such abusive acts on the victims themselves. Another limitation of the current study is that we confounded volume of abuse with content posted by timeline owners. By controlling this, future studies could support our explanation that the social-attractiveness and DVB interactions were driven by 'victim' popularity. Varying the specific content of abusive posts could provide insight into different types of attractiveness (e.g., task-attractiveness in workplace-bullying) or effects on male vs. female 'victims' (Walther et al., 2008). Our study also only measured DVB. It would also be interesting to examine perceived incident severity or indirect VB (as measured by Weber et al., 2013) in addition to DVB. It might be expected that fewer abusive posts would elicit a perception of a less sever incident, though if volume of third party content on social media is a cue of popularity and an indicator of attractiveness such perceptions might not manifest, or may be determined by the specific content of the abusive posts. Finally, all 'victims' in the current study were young Caucasians. In future, it would be interesting to investigate differences in perceptions of 'victims' of distinct ages, races, and sexes.

\section{Conclusions}

The purpose of the current study was to investigate the combined effects of Volume and Source of online abuse on attributions of VB and perceptions of 'victims' attractiveness. Significant interactions between Volume and Source were observed on measures of DVB and social-attractiveness. When relatively few abusive posts were generated by a single-author source, DVB was greater than in other conditions (e.g., higher volumes, multiple sources); this effect was mirrored in perceptions of social-attractiveness: 'victims' who received few posts from single sources were perceived as least socially-attractive. We argue that the 
pattern of effects may represent desensitization to online abuse on the part of observers, or an interpretation of a high volume of social interaction as friendly and/or non-malicious regardless of content. These findings demonstrate that Volume and Source - commonly used to define different sub-categories of cyberabuse - are instrumental in determining (cyber)bystanders' perceptions of 'victims'. 


\section{References}

Alexy, E.M., Burgess, A.W., Baker, T., \& Smoyak, S.A. (2005). Perceptions of cyberstalking among college students. Brief Treatment and Crisis Intervention, 5(3), 279-289. doi:10.1093/brief-treatment/mhi020

Baldasare, A., Bauman, S., Goldman, L., \& Robie, A. (2012), Chapter 8 Cyberbullying? Voices of College Students, in Laura A. Wankel, Charles Wankel (Eds.) Misbehavior Online in Higher Education (Cutting-edge Technologies in Higher Education, Volume 5) Emerald Group Publishing Limited, pp.127 - 155

Barlinska, J., Szuster, A., \& Winiewski, M. (2013). Cyberbullying among adolescent bystanders: Role of the communication medium, form of violence, and empathy. Journal of Community and Applied Social Psychology, 23, 37-51. http://dx.doi.org/10.1002/casp.2137

Bartholow, B.D., Bushman, B.J., \& Sestir, M.A. (2006). Chronic violent video game exposure and desensitization to violence: Behavioral and event-related brain potential data. Journal of Experimental Social Psychology, 42, 532-539.

Bocij, P. (2004). Cyberstalking: Harassment in the Internet Age and how to Protect your Family. Westport, CT: Praeger Publishers.

Citron, D.K. (2009). Cyber Civil Rights. Boston University Law Review, 61(89), 61-125.

Copeland, W.E., Wolke, D., Lereya, S.T., Shanahan, L., Worthman, C., \& Costello, J.E. (2014). Childhood bullying involvement predicts low-grade systemic inflammation into adulthood. Proceedings of the National Academy of Sciences, 111(21), 75707575 .

Crick, N.R., Grotpeter, J.K., \& Bigbee, M.A. (2002). Relationally and physically aggressive children's intent attributions and feelings of distress for relational and instrumental peer provocations. Child Dev. 73(4),1134-42.

Crosslin, K. \& Golman, M. (2014). "Maybe you don't want to face it" - College students' perspectives on cyberbullying. Computers in Human Behvaior, 41, 14-20. doi: $\underline{10.1016 / j . c h b .2014 .09 .007}$

DeSmet, A., Bastiaensens, S., Van Cleemput, K., Poels, K., Vandebosch, H., \& De Bourdeaudhuij, I. (2012). Mobilizing bystanders of cyber-bullying: An exploratory study into behavioural determinants of defending the victim. Annual Review of Cybertherapy and Telemedicine, 58-63.

Dion, K.K., Berscheid, E., \& Walster, E. (1972). What is beautiful is good. Journal of Personality and Social Psychology, 24(3), 285-290. doi:10.1037/h0033731 
Dooley, J., Pyzalski, J., \& Cross, D. (2009). Cyberbullying versus face-to-face bullying a theoretical and conceptual review. Journal of Psychology, 217, 182-188.

Einarsen, S. \& Skogstad, A. (2008). Bullying at work: Epidemiological findings in public and private organizations. European Journal of Work \& Organisational Psychology, 5, 185-201. doi: 10.1080/13594329608414854

Ellison, N., Steinfield, C., \& Lampe, C. (2007). The benefits of Facebook "friends"': Exploring the relationship between college students' use of online social friends networks and social capital. Journal of Computer-Mediated Communication, 12(4), $1143-1168$.

Fegenbush, B. \& Oliver, D.F. (2009). Cyberbullying: A review of the literature. Paper presented at the Annual Meeting of the Louisiana Education Research Association Lafayette March 5-6, 2009.

Finn, J. (2004). A survey of online harassment at a university campus. Journal of Interpersonal Violence, 19(4), 468-483.

Freis, S.D., \& Gurung, R.A.R. (2013). A Facebook analysis of helping behaviour in online bullying. Psychology of Popular Media Culture, 2, 11-19.

Gahagan, K., Vaterlaus, J.M., \& Frost, L.R. (2016). College student cyberbullying on social networking sites: Conceptualization, prevalence, and perceived bystander responsibility. Computers in Human Behavior, 55(B), 1097-1105. doi: $\underline{10.1016 / j . c h b .2015 .11 .019}$

Garett, R., Lord, L.R., \& Young, S.D. (2016). Associations between social media and cyberbullying: a review of the literature. MHealth, 2(46), doi: 10.21037/mhealth.2016.12.01

Hancock, J.T., \& Dunham, P.J. (2001). Impression formation in computer-mediated communication revisited: An analysis of the breadth and intensity of impressions. Communication Research, 28(3), 325-347.

Hinduja, S., \& Patchin, J. (2010). Bullying, cyberbullying, and suicide. Archives of Suicide Research, 14, 206-221.

Hoover, J.H., \& Olson, G. (2000). Sticks and Stones May Break Their Bones: Teasing as Bullying. Reclaiming Children and Youth, 9(2), 87-91.

Juvonen, J., \& Gross, E. (2008). Extending the school grounds? Bullying experiences in cyberspace. Journal of School Health, 78(9), 496-505. 
Kota, R., Schoohs, S., Benson, M., \& Moreno, M.A. (2014). Characterizing Cyberbullying among College Students: Hacking, Dirty Laundry, and Mocking. Societies, 4, 549 560.

Kowalski, R.M., Limber, S.P., \& Agatston, P.W. (2009). Cyber Bullying: Bullying in the digital age. Oxford, UK: Blackwell.

Langos, C. (2012). Cyberbullying: The Challenge to Define. Cyberpsychology, Behavior, and Social Networking, 15(6): 285-289. doi: 10.1089/cyber.2011.0588

Lee, R. (1998). Romantic and Electronic Stalking in a College Context, William and Mary Journal of Women and the Law, 4, 373-466.

Lerner, M., \& Simmons, C.H. (1966). Observer's Reaction to the 'Innocent Victim': Compassion or Rejection? Journal of Personality and Social Psychology, 4(2), 203210.

Maple, C., Short, E., Brown, A., Bryden, C., \& Salter, M. (2012). Cyberstalking in the UK: Analysis and Recommendations. International Journal of Distributed Systems and Technologies, 3(4), 34-51.

McCroskey, J.C., \& McCain, T.A. (1974). Measurement of interpersonal attraction. Speech Monographs, 41, 261-266.

McGrath, M.G., \& Casey, E. (2002). Forensic psychiatry and the internet: Practical perspectives on sexual predators and obsessional harassers in cyberspace. Journal of the American Academy of Psychiatry and the Law, 30(1), 81-94.

McKelvie, S. J., \& Coley, J. (1993). Effects of crime seriousness and offender facial attractiveness on recommended treatment. Social Behavior and Personality: an International Journal, 21(4), 265-277. doi:10.2224/sbp.1993.21.4.265

McQuade, S. (2012). Cyberstalking and Cyberbullying (Cybersafety). New York: Chelsea House Publishers.

Mechanic, M.B., Uhlmansiek, M.H., Weaver, T.L., \& Resick, P.A. (2000). The impact of severe stalking experienced by acutely battered women: An examination of violence, psychological symptoms, and strategic responding. Violence and Victims, 15, 443458.

Menesini, E., \& Nocentini, A. (2009). Cyberbullying definition and measurement: Some critical considerations. Journal of Psychology, 217(4), 230-232.

Menesini, E., Nocentini, A., Palladino, B.E., Frisén, A., Berne, S., Ortega-Ruiz, R., Calmaestra, J., Scheithauer, H., Schultze-Krumbholz, A., Luik, P., Naruskov, K., 
Blaya, C., Berthaud, J., \& Smith, P.K. (2012). Cyberpsychology, Behavior, and Social Networking, 15(9): 455-463.https://doi.org/10.1089/cyber.2012.0040

Modecki, K.L., Minchin, J., Harbaugh, A.G., Guerra, N.G., \& Runions, K.C. (2014).

Bullying prevalence across contexts: A meta-analysis measuring cyber and traditional bullying. Journal of Adolescent Health, 55, 602-611.

Molluzzo, J.C., \& Lawler, J. (2012). A study of the perceptions of college students on cyberbullying. Information Systems Education Journal, 10(4), 84-109.

Mullen, P., Pathé, M., \& Purcell, R. (2004). Stalking: Defining and prosecuting a new category of offending. International Journal of Law and Psychiatry, 27, 157-169.

Nocentini, A., Calmaestra, J., Schultze-Krumbholz, A., Scheithauer, H., Ortega, R., \& Menesini, E. (2010). Cyberbullying: Labels, behaviours and definition in three European countries. Journal of Psychologists and Counsellors in Schools, 20(2), 129142.

Novo, F., Pereira, F., \& Matos, M. (2014). Cyber-aggression among Portuguese adolescents: A study on perpetration, victim offender overlap and parental supervision. International Journal of Cyber Criminology, 8(2), 94-110.

Olweus, D. (2012). Cyberbullying: An overrated phenomenon? European Journal of Developmental Psychology, 9(5), 520-538.

Parks, M.R. \& Floyd, K. (1996). Making Friends in Cyberspace. Journal of ComputerMediated Communication, 1(4), JCMC144. https://doi.org/10.1111/j.10836101.1996.tb00176.x

Perren, S., Dooley, J., Shaw, T., \& Cross, D. (2010). Bullying in school and cyberspace: Associations with depressive symptoms in Swiss and Australian adolescents. Child and Adolescent Psychiatry and Mental Health, 4, 1-10.

Reyns, B.W. (2010). A Situational Crime Prevention Approach to Cyberstalking Victimization: Preventive Tactics for Internet Users and Online Place Managers. Crime Prevention and Community Safety, 12, 99-118.

Rosenthal-Stott, H.E., Dicks, R.E., \& Fielding, L.S. (2015). The valence of self-generated (status updates) and other generated (wall-posts) information determines impression formation on Facebook. PLoS One, 10:e0125064.

Russell, K.J., \& Hand, C.J. (2017). Rape Myth Acceptance, Victim Blame Attribution and Just World Beliefs: A Rapid Evidence Assessment. Aggression and Violent Behaviour, 37, 153-160. https://doi.org/10.1016/j.avb.2017.10.008 
Salmivalli, C. (2010). Bullying and the peer group: A review. Aggression and Violent Behaviour, 15(2), 112-120.

Salmivalli, C., Lagerspetz, K., Björkqvist, K., Österman, K., \& Kaukiainen, A. (1996). Bullying as a group process: Participant roles and their relations to social status within the group. Aggressive Behavior, 22, 1-15.

Scott, G.G. (2014). More than friends: Popularity on Facebook and its role in impression formation. Journal of Computer-Mediated Communication, 19(3), 358-372.

Scott, G.G., \& Hand, C.J. (2016). Motivation determines Facebook viewing strategy: An eye movement analysis. Computers in Human Behavior, 56, 267-280.

Scott, G.G., Sinclair, J., Short, E., \& Bruce, G. (2014). It's Not What You Say, It's How You Say It: Language Use on Facebook Impacts Employability But Not Attractiveness. Cyberpsychology, Behavior, and Social Networking, 17(8): 562-566. https://doi.org/10.1089/cyber.2013.0584

Scott, G.G. \& Ravenscroft, K. (2017). Bragging on Facebook: The interaction of content source \& focus on online impression formation. Cyberpsychology, Behavior, \& Social Networking, 20(1), 58-63. doi: 10.1089/cyber.2016.0311

Selwyn, N. (2008). A safe haven for misbehaving? An investigation of online misbehaviour among university students. Social Science Computer Review, 26(4), 446-465.

Shaver, K.G. (1970). Defensive attribution: effects of severity and relevance on the responsibility assigned for an accident. Journal of Personality and Social Psychology, $14,101-113$.

Sheridan, L.P., \& Grant, T. (2008). Is cyberstalking different? Psychology, Crime, \& Law, 13(6), 627-640.

Short, E., \& McMurray, I. (2009). Mobile phone harassment: An exploration of students' perceptions of intrusive texting behaviour. Human Technology, 5(2), 163-180.

Shultz, E., Heilman, R., \& Hart, K. J. (2014). Cyber-bullying: An exploration of bystander behavior and motivation. Cyberpsychology: Journal of Psychosocial Research on Cyberspace, 8(4), article 3. http://dx.doi.org/10.5817/CP2014-4-3

Skowronski, J., \& Ambady, N. (2008). First impressions: Rationales and roadmap. In N. Ambady \& J. Skowronski (Eds.) First Impressions. NY: Guilford.

Smith, P.K. (2012). Cyberbullying: Challenges and opportunities for a research program - A response to Olweus (2012). European Journal of Developmental Psychology, 9(5), 553-558. 
Smith, P. K., Mahdavi, J., Carvalho, M., Fisher, S., Russell, S., \& Tippett, N. (2008). Cyberbullying: Its nature and impact in secondary school pupils. Journal of Child Psychology and Psychiatry, 49, 376-385.

Spence Laschinger, H.K. \& Nosko, A. (2013). Exposure to workplace bullying and posttraumatic stress disorder symptomology: the role of protective psychological resources. Journal of Nursing Management, 23(2), 252-262. doi: 10.1111/jonm.12122

Spitzberg, B.H., \& Hoobler, G. (2002). Cyberstalking and the technologies of interpersonal terrorism. New Media \& Society, 4(1), 71-92.

Stefanone, M.A., Lackaff, D., \& Rosen, D. (2011). Contingencies of Self-Worth and SocialNetworking-Site Behavior. Cyberpsychology, Behavior, and Social Networking, 14, 41-49. https://doi.org/10.1089/cyber.2010.0049

Tennant, J.E., Demaray, M.K., Coyle, S., \& Malecki, C.K. (2015). The dangers of the web: Cybervictimization, depression, and social support in college students. Computers in Human Behavior, 50, 348-357. doi: 10.1016/j.chb.2015.04.014

Thornberg, R., Tenenbaum, L., Varjas, J., Meyers, K., Jungert, T., \& Vanegas, G. (2012). Bystander motivation in bullying incidents: To intervene or not to intervene. Western Journal of Emergency Medicine, 13, 247-252.

Thorndike, E.L. (1920). A constant error in psychological ratings. Journal of Applied Psychology, 4(1), 25-29. doi:10.1037/h0071663.

Tokunaga, R.S., (2010). Following you home from school: A critical review and synthesis of research on cyberbullying victimization. Computers in Human Behavior, 26(3), $277-$ 287. doi: https://doi.org/10.1016/j.chb.2009.11.014)

Tong, S.T., Van Der Heide, B., Langwell, L., \& Walther, J.B. (2008). Too much of a good thing? The relationship between number of friends and interpersonal impressions on Facebook. Journal of Computer-Mediated Communication, 13(3), 531-549.

Tragesser, S.L., \& Lippman, L.G. (2010). Teasing: For Superiority or Solidarity? The Journal of General Psychology, 132:3, 255-266, doi: 10.3200/GENP.132.3.255-266

Utz, S. (2010). Show me your friends and I will tell you what type of person you are: How one's profile, number of friends, and type of friends influence impression formation on social network sites. Journal of Computer-Mediated Communication, 15, 314-335

Vandebosch, H. \& Van Cleemput, K. (2008). Defining Cyberbullying: A Qualitative Research into the Perceptions of Youngsters. CyberPsychology \& Behavior, 11(4): 499-503. doi: $\underline{10.1089 / \mathrm{cpb} .2007 .0042}$ 
van Geel, M., Vedder, P., Tanilon, J. (2014). Relationship between peer victimization, cyberbullying, and suicide in children and adolescents: A meta-analysis. JAMA Pediatrics, 168(5), 435-442.

Walther, J.B. (1996). Computer-mediated communication: Impersonal, interpersonal, and hyperpersonal interaction. Communication Research, 23(1), 3-43.

Walther, J.B. (1997). Group and interpersonal effects in international computer-mediated collaboration. Human Communication Research, 23(3), 342-369.

Walther, J.B., Van Der Heide, B., Hamel, L.M., \& Shulman, H.C. (2009). Self generated versus other-generated statements and impressions in computer-mediated communication: a test of warranting theory using Facebook. Communication Research, 36(2), 229-252. https://doi.org/10.1177/0093650208330251

Walther, J.B., Van Der Heide, B., Kim, S.Y., Westerman, D., \& Tong, S.T. (2008). The role of friends' appearance and behavior on evaluations of individuals on Facebook: Are we known by the company we keep? Human Communication Research, 34(1): 28-49.

Weber, M., Ziegele, M., \& Schnauber, A. (2013). Blaming the victim: The effects of extraversion and information disclosure on guilt attributions in cyberbullying. Cyberpsychology, Behavior, and Social Networking, 16(4), 254-259.

Welling, L.L.M., Jones, B.C., DeBruine, L.M., Conway, C.A., Law Smith, M.J., Little, A.C., Feinberg, D.R., Sharp, M.A., \& Al-Dujaili, E.A.S. (2007). Raised salivary testosterone in women is associated with increased attraction to masculine faces. Hormones and Behavior, 52, 156-161. 
Appendix I

Stimulus Example (high volume, single-source) 


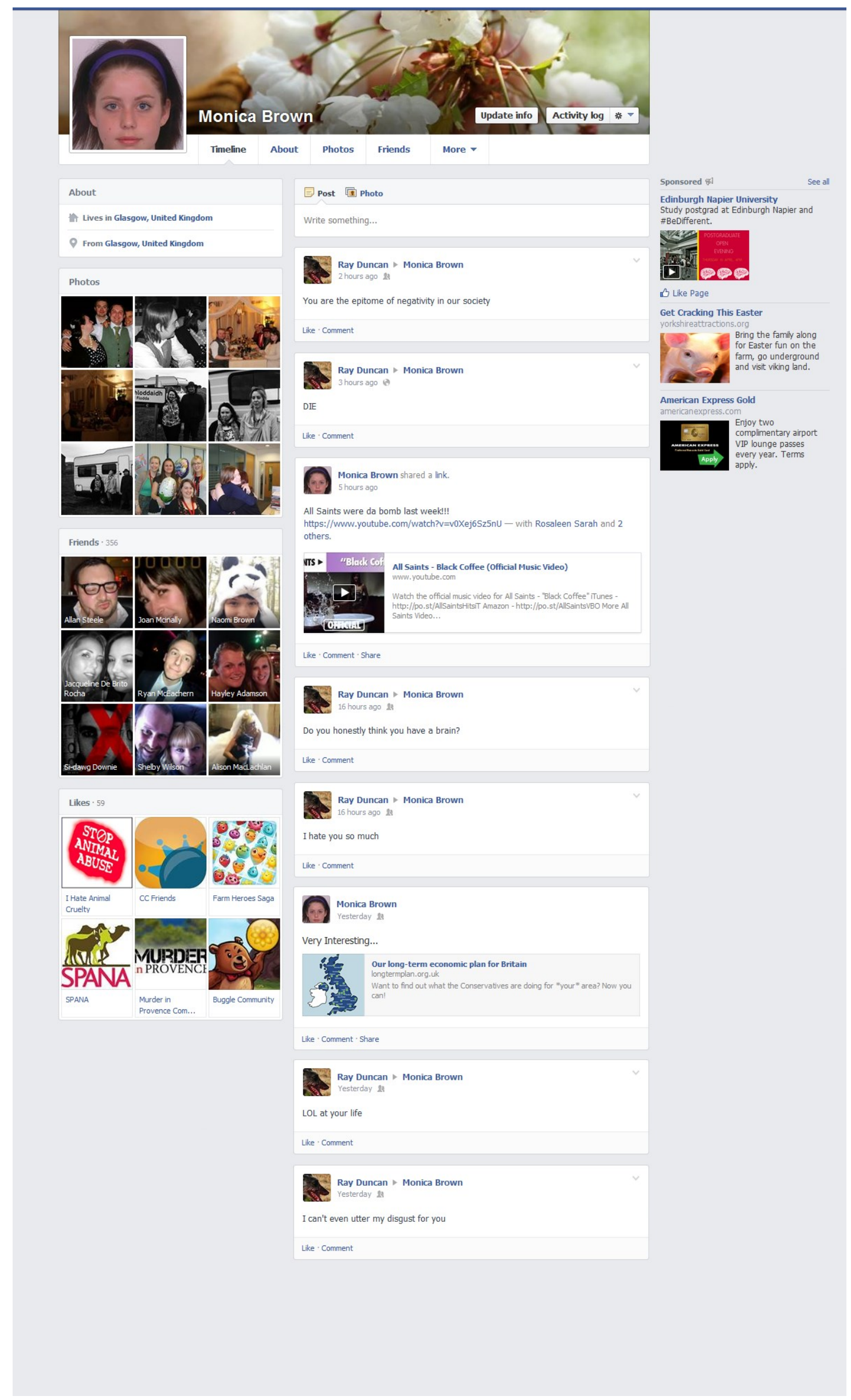

